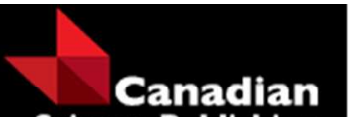

Science Publishing

Canadian Journal of Forest Research Revue canadienne de recherche forestière

\title{
Simple inheritance of a complex trait: figured wood in curly birch is caused by one semi-dominant and lethal Mendelian factor?
}

\begin{tabular}{|r|l|}
\hline Journal: & Canadian Journal of Forest Research \\
\hline Manuscript ID & cjfr-2017-0007.R1 \\
\hline Manuscript Type: & Note \\
\hline Complete List of Authors: & $\begin{array}{l}\text { Kärkkäinen, Katri; Natural Resources Institute Finland, Green Technology } \\
\text { Viherä-Aarnio, Anneli; Natural Resources Institute Finland, Green } \\
\text { Techonology } \\
\text { Vakkari, Pekka; Natural Resources Institute Finland, Green Techonology } \\
\text { Hagqvist, Risto; Natural Resources Institute Finland, Green Techonology } \\
\text { Nieminen, Kaisa; Natural Resources Institute Finland, Green Techonology }\end{array}$ \\
\hline Keyword: & Betula, figured wood, wood quality, curly birch, genetics \\
\hline $\begin{array}{r}\text { Is the invited manuscript for } \\
\text { consideration in a Special } \\
\text { Issue? : }\end{array}$ & N/A \\
\hline
\end{tabular}

\section{SCHOLARONE ${ }^{\text {m }}$ \\ Manuscripts}


8 Simple inheritance of a complex trait: figured wood in curly birch is caused by one semi-

9 dominant and lethal Mendelian factor?

12 Kärkkäinen, K., Viherä-Aarnio, A., Vakkari, P., Hagqvist, R. \& Nieminen, K.

13 Natural Resources Institute Finland (Luke) 1) Luke, Oulu, Paavo Havaksen tie 3, 90014

14 University of Oulu Finland; 2,3,4,5) Luke, Helsinki, Latokartanonkaari 9, 00790 Helsinki

15 Finland (e mails: katri.karkkainen@luke.fi; anneli.vihera-aarnio@luke.fi,

16 pekka.vakkari@luke.fi; risto.hagqvist@luke.fi; kaisa.nieminen@luke.fi)

17 Corresponding author:

18 Katri Kärkkäinen, Luke Oulu Paavo Havaksen tie 3, 90014 University of Oulu, e mail

19 katri.karkkainen@luke.fi 


\section{Abstract:}

2 Even though individuals with a deviant morphology have been elemental in genetics of 3 model species, they have thus far been largely ignored in the studies of forest trees. Here 4 we studied the inheritance of curly-grained and brown-figured wood phenotype in curly

5 birch (Betula pendula var. carelica). In addition of the figured wood, curly birches display

6 reduced and aberrant growth, indicating that the causative locus/loci is/are vital for normal

7 tree development. To explore the genetic basis of this mutation, we studied the inheritance

8 of curly birch phenotype in a progeny trial (crosses between curly birch parent trees,

9 between curly and normal phenotypes, and from selfings of curly trees). Based on the external morphology, the phenotype of 11-year-old progeny trees was scored as either curly

11 or wild. Based on the phenotypic segregation ratios, we postulate a simple Mendelian 12 inheritance model for curliness: (i) one locus, two-allele model in which the allele coding for 13 curly phenotype is dominant over the allele coding for normal phenotype and (ii) the semi14 dominant curly allele is lethal when homozygous. We expect that further studies on the molecular genetic basis of the curly birch phenotype will provide valuable information on

16 the developmental pathways involved in wood formation.

Key words: Betula, curly birch, figured wood, genetics, wood quality 


\section{Introduction}

2 Wood represents a renewable source of lignocellulosic biomass with immense commercial

3 value and the genetic regulation of wood development is important target for tree breeding

4 efforts. Formation of wood is a complex process involving cell division, cell expansion,

5 secondary wall synthesis, and programmed cell death. Thus far a forward genetics approach

6 in annual model species, specifically Arabidopsis, has been elemental in increasing our

7 understanding about molecular mechanisms behind wood development (Nieminen et al.

8 2015). This approach relies on the study of mutant phenotypes combined with the

9 identification of the underlying gene functions. Despite the progress, we are still lacking in our genetic understanding of the regulatory networks behind wood formation.

11 Mutant phenotypes are not limited to annual species: deviant morphological types have

12 been described in many tree species, and these mutations have been grafted in clone collections or vegetatively propagated and utilized in horticulture for their ornamental value. Yet these mutant phenotypes have thus far been largely ignored in molecular studies; very little is currently known of their genetic basis.

One relatively common aberrant phenotype present in natural tree populations is figured wood, i.e., wood which displays patterns or markings on its longitudinal surfaces. This wood type is valued for its use in furniture, paneling, and other decorative applications. A wide range of patterns has been described for the figured wood; their names, including e.g. burl, birdseye, fiddleback, blister, quilted, and curly, reflect this variation. Only a few studies have addressed the potential developmental mechanisms behind figured wood production, yet, the possibility to clone the figured phenotypes by grafting (McKenna et al. 2015), rooted 
1 cuttings (Fan et al. 2013 ) or through tissue culture propagation (Ryynänen and Ryynänen

2 1986) indicates that the phenotype has a genetic basis. Understanding the genetics of

3 figured phenotypes would enable more targeted breeding - and identification of the

4 causative genetic factors would provide valuable information about the developmental

5 pathways behind wood formation.

6 One well-known figured wood mutant is curly birch (Betula pendula var. carelica (Mercklin)

7 Hämet-Ahti), a silver birch variant famous for its highly decorative curly-grained and brown-

8 figured wood. It occurs naturally in Northern Europe and parts of Eastern and Central

9 Europe, however, it is rare throughout its distribution range. Curly birch is by far the most

10 highly-priced variant of a native tree species in Nordic countries: its wood is used for

11 furnishing as well as manufacturing gifts, souvenirs, tools, furniture and other commercial

12 products.

13 During formation of wood, cambium cells of curly birch have disturbed rhythm in activity compared to normal cambial activity: some cease to divide while surrounding cells divide

15 rapidly causing wound callus and bark parenchyma being incrusted in the wood (Velling et al

2000). As a result, annual rings become wavy, orientation of tissue non-normal and pith rays

17 dilated. In the cross section of a curly birch stem, V-shaped patterns are seen, which can form a pronounced and closed "curly flower" configuration (Figure 1b). When the bark is peeled off, the surface of the stem has a granulated appearance with small oblong swellings and depressions. A longitudinal tangential cut shows a curly configuration (Figure 1c).

21 In addition to altered wood structure, curly birch trees show morphological variation: their growth form varies from crooked multi-stemmed bushes to straight single-stemmed trees. 
1 The trunk, which is typically shorter than that of normal silver birch, is often forked and

2 leaning, contains swellings, knots and protuberances and is covered by thick, cracked and

3 partly black bark. The single-stemmed individuals with abundant protuberance formation

4 and rich curly configuration in the wood are suitable for turning (veneering) and therefore

5 commercially most valuable (Figure 1a).

6 Many different hypotheses have been suggested for the origin of curly phenotype in birch,

7 varying from effects of disease to genetic inheritance with one major gene or several minor

8 genes (see Velling et al. 2000 and references therein). Here we report an analysis of crosses

9 studying the inheritance of curly birch phenotype: our results indicate a relatively simple

10 Mendelian inheritance based on one (semi-)dominant, lethal as homozygous, curly locus.

\section{Materials and Methods}

12 Genetic material and field trial

13 Crosses analyzed in this study were designed and produced for testing and comparing progenies from commercially most valuable curly birch parent trees. Crosses were carried out in a curly birch seed orchard (no 353 in a polythene greenhouse at Haapastensyrjä Tree Breeding Station). The field trial included crossed progenies produced in a partial diallel crossing design, together with some selfings and crosses with pollen mixtures. In this study, we included only the progenies from crosses where parent tree(s) unambiguously expressed the most valuable curly phenotype, i.e. single-stemmed, straight trees with clear protuberance formation on the surface of the stem (see Figure 1a). In uncertain cases the presence of brown figures was confirmed by taking wood samples with an increment bore from the grafts of parent trees in the seed orchard 353. Thus, the final analysis included 24 
1 full-sib families from crossings between curly birch parent trees, 6 poly cross and 1 open-

2 pollinated families from controlled pollination of curly birch by a pollen mixture of normal

3 phenotype silver birch (pollen from 9 trees) and 4 full-sib families from self-pollination of

4 curly birch trees. Total number of curly birch parent trees included was $\mathbf{1 1}$ (9 as mothers, 9

5 as fathers, Table 1$)$.

6 Seedlings were raised in the nursery, and the trial (no 1181/1) was established with 1-year-

7 old containerized (Tako-1210) seedlings in early June 1987 in Loppi southern Finland

$8 \quad\left(60^{\circ} 45^{\prime} \mathrm{N}, 24^{\circ} 11^{\prime} \mathrm{E}, 110 \mathrm{~m}\right.$ a.s.l.). Seedlings were planted in a completely randomized block

9 design with five blocks and progenies were randomized to the multiple tree plots (12

10 seedlings/plot), plot size being $6 \mathrm{~m} \times 10 \mathrm{~m}$ and spacing $2 \mathrm{~m} \times 2.5 \mathrm{~m}$. The number of

11 seedlings planted per family was aimed to be 60 . However, due to lack of seeds and

12 seedlings in some families lower numbers of seedlings were planted (Table 1). The trial was

13 established on agricultural land. During the early development, the trial area was managed

14 by weeding, and the seedlings were once protected from voles by application of Viltex

15 volerepellent. No thinnings were conducted before the measurements.

Scoring of the phenotype

A non-destructive visual assessment of curliness was based on the externally visible morphology and conducted on the 11-year-old birch trees in spring 1997. A tree was classified as "curly" if it clearly manifested externally visible morphological characteristics of the stem, i.e. swellings, knots or protuberances, which usually indicate internal curly wood

21 formation with brown figures within the stem. Often these traits appeared together with a leaning, forked or bushy growth habit. When no externally visible symptoms were detected, 
1 the tree was classified as normal, "wild-type" silver birch. Basically the assessment was done

2 to all living trees, but also dead trees tall enough to manifest curliness were included.

3 Altogether 1615 trees were assessed. In addition to scoring the phenotype, data on

4 mortality and tree size, i.e. tree height $(\mathrm{dm})$ and diameter $(\mathrm{mm})$ over bark at $1.3 \mathrm{~m}(\mathrm{dbh})$

5 were recorded.

6 Data analysis

7 Based on the results of the crosses (see below), we postulated a simple Mendelian model

8 for inheritance of curly figure: (i) one gene, two-allele model in which the allele coding for

9 curly phenotype is dominant over the allele coding for normal, wild-type phenotype and

10 further, (ii) dominant curly allele is lethal when homozygous. The fit of models were

11 evaluated by testing the following predictions: if curly phenotype (C) is caused by one

12 dominant allele (case i), selfings of curly birch and $\mathrm{C} \times \mathrm{C}$ crosses should produce both curly

13 and wild type (W) phenotypes in 3:1 ratio. If the curly phenotype $(\mathrm{C})$ is caused by dominant

14 allele that is lethal as homozygous (case ii), selfings of curly birch and C $\mathrm{C}$ crosses should

15 produce both curly and normal wild-type (W) phenotypes in 2:1 ratio and crosses between

16 curly and normal phenotypes should produce 1:1 C:W phenotypes. For crosses, deviations

17 from expected ratios of curly and normal phenotypes were examined with $\chi^{2}$-tests. This was

18 done separately for each cross with large number of offspring $(N=60)$, and for data pooled

19 over each cross type ( $\mathrm{C}$ self, $\mathrm{C} \times \mathrm{C}, \mathrm{C} \times \mathrm{W}$ ). An analysis of variance was applied to test the

20 differences in height and diameter between curly and normal type trees within each

21 crossing type separately using progeny means for curly and normal type.

\section{Results}


1 Altogether 11 individual curly genotypes were used in the crosses, and altogether 1615

2 trees were phenotyped. All selfings of curly birches ( $C$ self), crosses between any two curly

3 phenotypes $(C \times C)$, or between curly and normal phenotypes $(C \times W)$ produced trees with

4 both C and W phenotypes; no cross producing only curly phenotype was found, only

5 segregating progenies (Table 1). Proportion of the curly phenotype in the progenies of $\mathrm{C} \times \mathrm{W}$

6 crosses was generally lower than in the $\mathrm{C} \times \mathrm{C}$ crosses and $\mathrm{C}$ selfings (Table 1 ; Table 2).

7 In all the individual $\mathrm{C}$ selfings and $\mathrm{C} \times \mathrm{C}$ crosses, the ratio of 2:1 of C:W fitted data better

8 than 3:1 ratio (Table 1). However, significant deviations from the expected 2:1 ratio were

9 observed in four of the 28 crosses (Table 1 ) and pooled analyses of different crossing types

10 show a general deviation from the 2:1 ratio in $C$ selfings and $C \times C$ crosses (Table 2).

11 In all crosses between curly and normal, wild-type phenotype ( $C \times W$ ), the observed

12 numbers of both phenotypes among offspring closely followed the 1:1 ratio, with the 13 percentage of curly progeny varying between $44-54 \%$ (Table 1 ). In the $\mathrm{C} \times \mathrm{W}$ crosses, curly

14 phenotype was always used as maternal and wild type as paternal tree. However, very

15 similar results were obtained in another, smaller crossing experiment, where the wild type

16 trees were used as mothers and crossed separately with different curly trees (Punkaharju

17 experiment no 2127, frequencies of curly phenotypes in progenies of $\mathrm{W} \times \mathrm{C}$ crosses varied 18 between $51.1 \%$ and $49.3 \%$, data can be obtained from authors), indicating that the

19 direction of the cross had no significance. Thus, there is no indication of cytoplasmic 20 involvement in the inheritance of curly phenotype. 
1 There was some variation in the mortality and growth between the progenies. The mortality

2 during the experiment was highest among selfed progenies (mean 25\%), and relatively

3 similar between $\mathrm{C} \times \mathrm{C}$ crosses (13\%) and C $\times$ W crosses (10\%).

4 The average size of the curly phenotype, as measured by both the stem height and

5 diameter, was smaller than that of the normal, wild-type phenotype in both the $\mathrm{C} \times \mathrm{C}$ (for

6 height, ANOVA $F=77,3, p<0.005$ for diameter $F=38.1 p>0.005$ ) and $C \times W$ crosses (For

7 height, $F=70.4, p<0.005$; for diameter $F=24.5$, however differences were not statistically

8 significant among selfed progenies probably due to small sample sizes and large variation

9 (Figure 2). 
1

\section{Discussion}

2 The phenotype frequencies in our crosses support the hypothesis of a dominant, lethal as

3 homozygous, curly allele over the case for a dominant, non-lethal allele. Dominance can be

4 inferred from the fact that all $\mathrm{C} \times \mathrm{W}$ crosses produced curly phenotypes. Homozygous

5 lethality would explain why segregation ratios from $\mathrm{C} \times \mathrm{C}$ crosses and curly selfings were

6 closer to 2:1 than 3:1. Furthermore, all crosses produced segregating progenies, indicating

7 that none of the curly individuals was homozygous for the curly locus.

8 In our study, $\mathrm{C} \times \mathrm{W}$ crosses followed the expected 1:1 ratio, whereas we observed an overall

9 deficiency of curly phenotypes in the selfings and $\mathrm{C} \times \mathrm{C}$ crosses; the deviation was more

10 pronounced in the selfings. Several factors may contribute to the observed deficiency:

11 possibly the inbreeding depression combined with the additional fitness strain of the curly

12 phenotype caused higher early mortality in the inbred curly trees than in the other

13 progenies. Furthermore, there most probably exist several allelic mutations of the curly

14 locus among our selection of curly parent trees: some may have weaker dominance and

15 lower phenotypic penetrance in the heterozygous state. We may have missed these alleles with lower penetrance in our C x W crosses, since they were not conducted with all of the parental curly trees.

Homozygous mortality may have occurred during embryo development or early seedling stage. Furthermore, some seeds that were sown in our study germinated but produced very small, dwarf seedlings that could not have survived in nature due to grass competition and thus were not planted in the field test. The proportion of dwarf seedlings was unfortunately not recorded in this experiment, but in another experiment the proportion of dwarf 
1 seedlings in $\mathrm{C} \times \mathrm{C}$ crosses was around 10\% (R. Hagqvist, personal communication, 2016). It

2 would be interesting to explore whether these dwarf trees might represent homozygous

3 curly trees which in some cases have survived past the embryonic state. Probably due to the

4 inbreeding depression, mortality among the selfed progenies was higher than among the

5 other crosses, and the average size of all trees was smaller than in the other cross types.

6 Although only individuals with a straight and single-stemmed growth form were selected for

7 parental trees in this study, some of the progeny trees still had bush-like phenotype

8 characterized by several trunks. Thus, the curly locus has influence on apical dominance,

9 either directly or more likely indirectly due to the complex and highly interconnected gene association networks of wood development and other vital traits and functions (Davin et al.

11 2016) where modification of any number of nodes within the network may result in multiple

12 habit shifts. Furthermore, observations in seed orchards in plastic houses suggest that

13 average flowering of curly phenotypes is more abundant than that of wild type (R. Hagqvist,

14 personal communication). Thus, although curly mutation has fitness effects both as

15 homozygous (lethality) and as heterozygous (reduced growth rate), high reproductive

16 output may explain why these mutations are found in natural populations.

17 Our hypothesis about the inheritance of curliness is not completely new: already Ruden 18 (1954) suggested that the curly phenotype might be due to one homozygotic lethal autosomal gene. However, at this time the idea was not largely accepted, probably due to

20 broad definition of the phenotype: in addition to the phenotype studied here, many other

21 kind of morphological deviants have previously been classified as curly birch, e.g. trunks

22 with longitudinal ridges, swollen muffs, rings etc. (Velling et al. 2000), some of which probably have different genetic basis and inheritance pattern. 
1 Interestingly, curly phenotype has been found to show a partly dominant inheritance also in

2 other species: Fan et al. (2013) studied figured grain in aspen (Populus x canescens), and

3 observed partially dominantly inherited segregation ratios that nevertheless did not follow

4 any simple Mendelian inheritance model. However, in the case of dioecious poplar, a

5 possible sex-linkage of the mutation, and segregation distortion in hybrid progeny

6 (backcross of curly $P$. alba $\times P$ tremula to $P$ alba) can additionally distort segregation ratios.

7 Dominant inheritance has been assumed also with other deviant morphological tree

8 phenotypes with possible fitness effects. For example, dominant genetic factor causes

9 witches broom in Pinus sibirica, a mutant phenotype that shows decreased apical

10 dominance, reduced shoot and needle length, male sterility and increased branching and

11 female cone bearing (Zhuk et al. 2015).

12 The fact that simple inheritance of curly phenotype involves dominance and lethality

13 suggests that the locus is vital for wood development. Understanding the genetic basis of 14 curly birch figured phenotype will therefore provide valuable information on the 15 developmental pathways involved in wood formation. When assessing the nature of the 16 curly locus, studies on model plants may prove to be valuable. Semidominant inheritance 17 and pleiotropic effects have previously been observed in Arabidopsis mutants with wood 18 formation phenotypes. For example, a mutation in the cellulose synthase gene AtCesA3 19 causes reduced cellulose content and a radially swollen root phenotype in a gene-dosage 20 dependent manner (Daras et al. 2009), whereas a semi-dominant gain-of-function allele of 21 REVOLUTA/IFL gene disturbs the vascular organization of Arabidopsis stem (Emery et al.

22 2003). Yet, although several suitable candidate genes for curly locus have already been 23 described, many more may still be completely unknown. 
1 Figured wood phenotype has been called "most desirable, least understood, and certainly

2 most complex characteristic of wood" (e.g. Fan et al. 2013 and references therein). Here we

3 suggest a case of simple answer for an old mystery. However, these "odd phenotypes" have

4 thus far been underutilized in genetic studies of forest tree species; hopefully in the near

5 future they can prove to be as useful in studies revealing genetic basis of complex 6 phenotypes and processes as in the model species. 
1 Acknowledgements

2 This study was funded by the Foundation for Forest Tree Breeding, the Finnish Forest

3 Research Institute and the Natural Resources Institute Finland. The authors wish to thank

4 the staff of Haapastensyrjä Tree Breeding Center for carrying out the crosses and for

5 establishing, scoring and measuring the progeny trial. The landowners of the trial, i.e. the

6 companies Oy Finlayson Ab, Asko Oy, and UPM Metsä are greatly acknowledged for

7 supporting the establishment and care of the field trial.

8

9 References

10 Daras, G., Rigas, S., Penning, B., Milioni, D., McCann, M.C., Carpita, N.C., Fasseas, C., and

11 Hatzopoulos, P. 2009. The thanatos mutation in Arabidopsis thaliana cellulose synthase 3

12 (AtCesA3) has a dominant-negative effect on cellulose synthesis and plant growth. New

13 Phytol. 184: 114-126. doi:10.1111/j.1469-8137.2009.02960.x

14 Davin, N., Edger, P.P., Hefer, C.A., Mizrachi, E., Schuetz, M., Smets, E., Myburg, A.A.,

15 Douglas, C.J., Schranz, M.E., and Lens, F. 2016. Functional network analysis of genes

16 differentially expressed during xylogenesis in soc1ful woody Arabidopsis plants. Plant J. 86:

17 376-390. doi:10.1111/tpj.13157.

Emery, J.F., Floyd, S.K., Alvarez, J., Eshed, Y., Hawker, N.P., Izhaki, A., Baum, S.F., and genes. Curr. Biol. 13, 1768-1774. 
1 Fan,Y., Rupert, K., Wiedenhoeft, A.C., Woeste, K., Lexer, C., and Meilan, R. 2013. Figured

2 grain in aspen is heritable and not affected by graft-tansmissible signals. Trees 27: 973-983.

3 doi: 10.1007/s00468-013-0849-1.

4 McKenna, J.R., Geyer, W.A., Woeste, K.E., and Cassens, D.L. 2015. Propagating figured wood

5 in black walnut. Open Journal of Forestry 2015 (5): 518-525.

$6 \quad$ http://dx.doi.org/10.4236/ojf.2015.55045.

7 Nieminen, K., Blomster, T., Helariutta, Y., and Mähönen, A.P. 2015. Vascular cambium

8 development. The Arabidopsis Book doi: http://dx.doi.org/10.1199/tab.0177

9 Ruden, T. 1954. On valbjørk og endel andre unormale veddannelser hos bjørk. Summary: On

10 spreckled birch ('mazer-birch') and some other forms of curled birch. Meddelelser fra Det

11 Norske Skogfors $\emptyset$ ksvesen 43: 455-505.

12 Ryynänen, L., and Ryynänen, M. 1986. Propagation of adult curly-birch succeeds with tissue 13 culture. Silva Fennica 20: 139-147.

14 Velling, P., Viherä-Aarnio, A., Hagqvist, R., and Lehto, J. 2000. Valuable wood as a result of

15 abnormal cambial activity - the case of Betula pendula var. carelica. InCell \& Molecular

16 Biology of Wood Formation. Edited by R. Savidge, J. Barnett and R. Napier. BIOS Scientific

17 Publishers Ltd, Oxford. 377-386.

18 Zhuk, E., Vasilyeva, G., and Goroshkevich, S. 2015. Witches' broom and normal crown clone

19 from the same trees of Pinus sibirica: a comparative morphological study. Trees 29: 1079-

20 1090. doi:10.1007/s00468-015-1187-2. 
1 Table 1. Results of curly birch crosses tested against major hypotheses of progeny

2 phenotype ratios under one locus model. Ratio 3:1 is expected under complete dominance

3 of curly allele over wild-type allele, ratio $2: 1$ if dominant curly allele is lethal as homozygous.

\begin{tabular}{|c|c|c|c|c|c|c|c|c|}
\hline \multicolumn{5}{|c|}{ Curly selfings } & \multicolumn{2}{|c|}{ Expected ratio 2:1 } & \multicolumn{2}{|c|}{ Expected ratio 3:1 } \\
\hline female & male & $\mathrm{n}^{a}$ & surv\% ${ }^{b}$ & curly $\%^{c}$ & $x^{2}$ & $p$ & $x^{2}$ & $p$ \\
\hline E4804 & E4804 & 12 & 58.3 & 42.9 & 1.786 & ns & 3.857 & $<0.05$ \\
\hline E4805 & E4805 & 23 & 73.9 & 47.1 & 2.941 & ns & 7.078 & $<0.01$ \\
\hline E4810 & E4810 & 60 & 93.3 & 58.9 & 1.509 & ns & 7.714 & $<0.01$ \\
\hline E6539 & E6539 & 60 & 75.0 & 55.6 & 2.500 & ns & 9.074 & $<0.01$ \\
\hline \multicolumn{5}{|c|}{ Curly x curly crosses } & \multicolumn{2}{|c|}{ Expected ratio 2:1 } & \multicolumn{2}{|c|}{ Expected ratio $3: 1$} \\
\hline female & male & $\mathrm{n}^{a}$ & surv ${ }^{b}$ & curly $\%^{c}$ & $x^{2}$ & $p$ & $x^{2}$ & $p$ \\
\hline E3460 & E3648 & 60 & 81.7 & 65.3 & 0.041 & ns & 2.456 & ns \\
\hline E3460 & E4806 & 60 & 91.7 & 78.2 & 3.282 & ns & 0.297 & ns \\
\hline E3460 & E4810 & 60 & 91.7 & 66.1 & 0.037 & ns & 2.005 & ns \\
\hline E3460 & E5649 & 10 & 100 & 60.0 & 0.200 & ns & 1.200 & ns \\
\hline E3460 & c-mix & 60 & 90.0 & 71.9 & 0.333 & ns & 0.617 & ns \\
\hline E3648 & E4810 & 48 & 72.9 & 65.7 & 0.014 & ns & 1.610 & ns \\
\hline E4804 & E4806 & 60 & 85 & 64.2 & 0.151 & ns & 3.327 & ns \\
\hline E4804 & E5649 & 12 & 100 & 41.7 & 3.375 & ns & 7.111 & $<0.01$ \\
\hline E4804 & E6539 & 60 & 90 & 58.9 & 1.509 & ns & 7.714 & $<0.01$ \\
\hline E4804 & c-mix & 48 & 95.8 & 46.8 & 8.341 & $<0.01$ & 19.922 & $<0.001$ \\
\hline E4806 & E3648 & 48 & 91.7 & 53.3 & 4.097 & ns & 12.121 & $<0.001$ \\
\hline E4806 & E4810 & 60 & 91.7 & 56.9 & 2.491 & ns & 10.138 & $<0.001$ \\
\hline E4806 & c-mix & 48 & 95.8 & 58.7 & 1.315 & ns & 6.522 & $<0.05$ \\
\hline
\end{tabular}




$\begin{array}{llllllclll}\text { E4810 } & \text { E3459 } & 60 & 93.3 & 85.7 & 9.143 & <0.01 & 3.429 & \text { ns } \\ \text { E4810 } & \text { E4804 } & 60 & 91.7 & 69.1 & 0.145 & \text { ns } & 1.024 & \text { ns } \\ \text { E4810 } & \text { E5084 } & 60 & 83.3 & 72.0 & 0.640 & \text { ns } & 0.240 & \text { ns } \\ \text { E4810 } & \text { E6539 } & 60 & 86.7 & 63.6 & 0.227 & \text { ns } & 3.788 & \text { ns } \\ \text { E5084 } & \text { E4804 } & 48 & 87.5 & 60.5 & 0.744 & \text { ns } & 4.845 & <0.05 \\ \text { E5084 } & \text { E4806 } & 48 & 72.9 & 52.4 & 3.857 & <0.05 & 11.460 & <0.001 \\ \text { E5084 } & \text { E6539 } & 60 & 66.7 & 57.5 & 1.513 & \text { ns } & 6.533 & <0.05 \\ \text { E6539 } & \text { E3300 } & 60 & 88.3 & 75.5 & 1.849 & \text { ns } & 0.006 & \text { ns } \\ \text { E6539 } & \text { 2-mix } & 60 & 76.7 & 65.2 & 0.043 & \text { ns } & 2.348 & \text { ns } \\ \text { E6539 } & \text { E5649 } & 48 & 87.5 & 42.9 & 10.714 & <0.01 & 23.143 & <0.001 \\ \text { E6539 } & \text { C-mix } & 60 & 83.3 & 62.7 & 0.353 & \text { ns } & 4.085 & <0.05\end{array}$

\section{Curly x normal crosses}

$\begin{array}{llrrrrr}\text { female } & \text { male } & \mathrm{n}^{a} & \text { surv\% }^{b} & \text { curly\% } & x^{c} & p \\ \text { E3460 } & \text { w-mix } & 60 & 91.7 & 53.6 & 0.286 & \text { ns } \\ \text { E3648 } & \text { w-mix } & 60 & 98.3 & 49.2 & 0.017 & \text { ns } \\ \text { E4804 } & \text { w-mix } & 60 & 90.0 & 49.1 & 0.000 & \text { ns } \\ \text { E4806 } & \text { w-mix } & 60 & 83.3 & 50.0 & 0.000 & \text { ns } \\ \text { E4810 } & \text { w-mix } & 60 & 88.3 & 44.4 & 0.667 & \text { ns } \\ \text { E6539 } & \text { w-mix } & 60 & 85.0 & 48.1 & 0.077 & \text { ns } \\ \text { E3300 } & \text { op } & 60 & 95.0 & 51.7 & 0.069 & \text { ns }\end{array}$

\section{Expected ratio 1:1}

(

1

2 NOTE: c-mix pollen mixture of curly birch from seed orchard 353; 2-mix pollen mixture of

3 two curly birches (E3460 and E4806); w-mix pollen mixture of wild type silver birch; op open

4 pollination in a silver birch forest.

$5{ }^{a}$ number of planted seedlings, ${ }^{b}$ survival (\%), ${ }^{c}$ proportion of curly trees (\%) 
1 Table 2. Summary of curly birch progenies tested against 2:1 (curly x curly) and 1:1 (curly $\mathrm{x}$ 2 wild-type) ratios.

\begin{tabular}{lrrrrrrr}
\hline Crossing type & $\mathbf{n}$ & $\begin{array}{c}\text { surv } \\
\text { \% }\end{array}$ & curly & wild & $\begin{array}{c}\text { C:W } \\
\text { ratio }\end{array}$ & $\mathbf{X}^{\mathbf{2}}$ & $\mathbf{p}$ \\
\hline $\begin{array}{l}\text { Curly selfings } \\
\text { Curly x curly crosses }\end{array}$ & 155 & 75.1 & 69 & 56 & $2: 1$ & 7.400 & $<0.01$ \\
$\begin{array}{l}\text { Curly x wild-type } \\
\text { crosses }\end{array}$ & 4258 & 87.3 & 692 & 395 & $2: 1$ & 4.420 & $<0.1$ \\
& & 90.2 & 188 & 191 & $1: 1$ & 0.024 & ns \\
\hline
\end{tabular}

3

4 NOTE: n number of planted seedlings; surv\% survival (\%); curly number of curly trees;

5 wild number of wild type trees.

6

7 

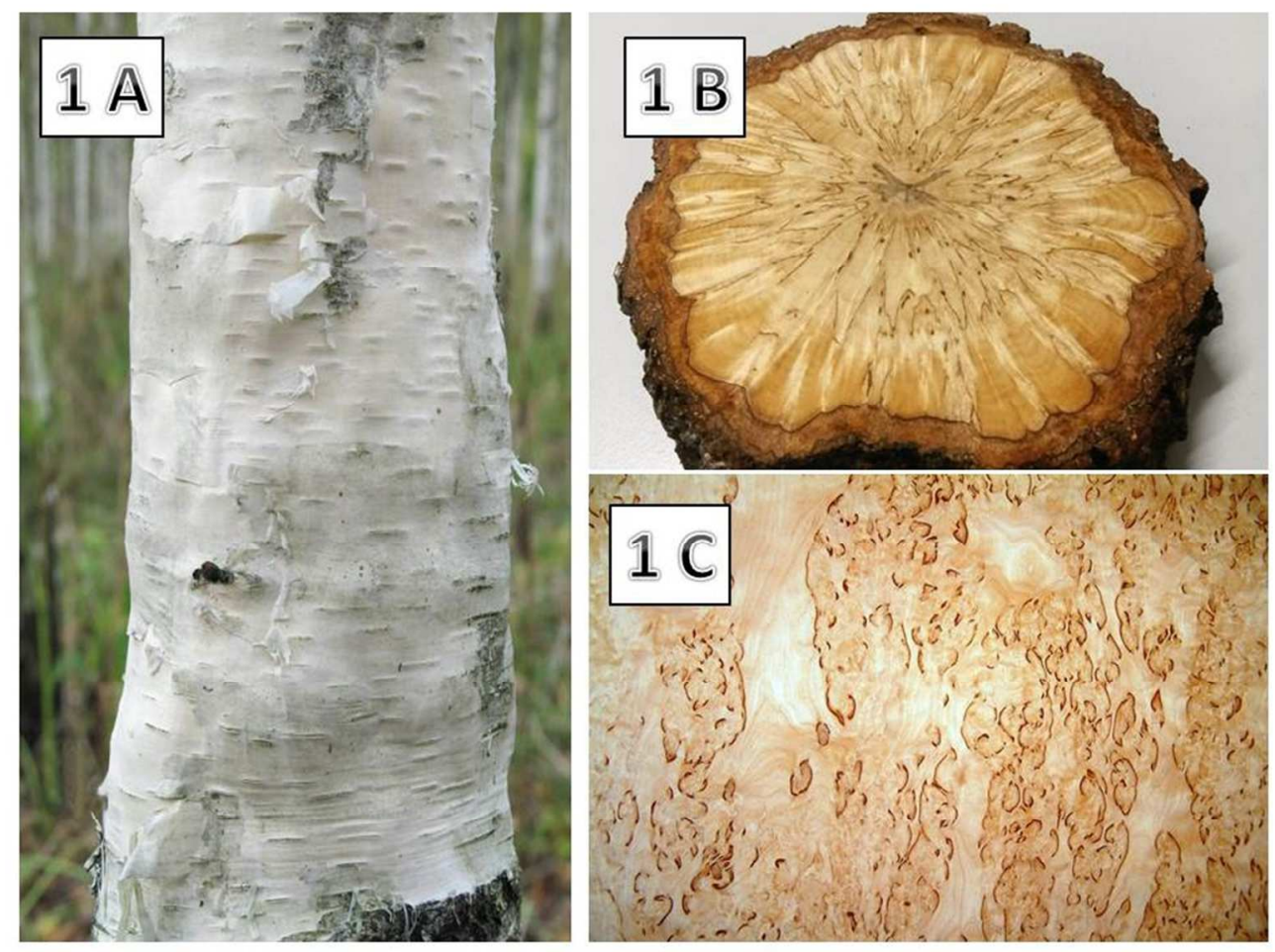

Figure 1. Curly birch. 1a. The straight, single-stemmed tree with an abundant and even protuberance formation, together with a rich brown configuration of the wood, is regarded as the most valuable type of curly birch. 1b. Transverse surface of a curly birch stem with the typical "flower" pattern. 1c. A piece of veneer produced from curly birch (Photographs: Luke/Risto Hagqvist).

$254 \times 190 \mathrm{~mm}(96 \times 96$ DPI) 


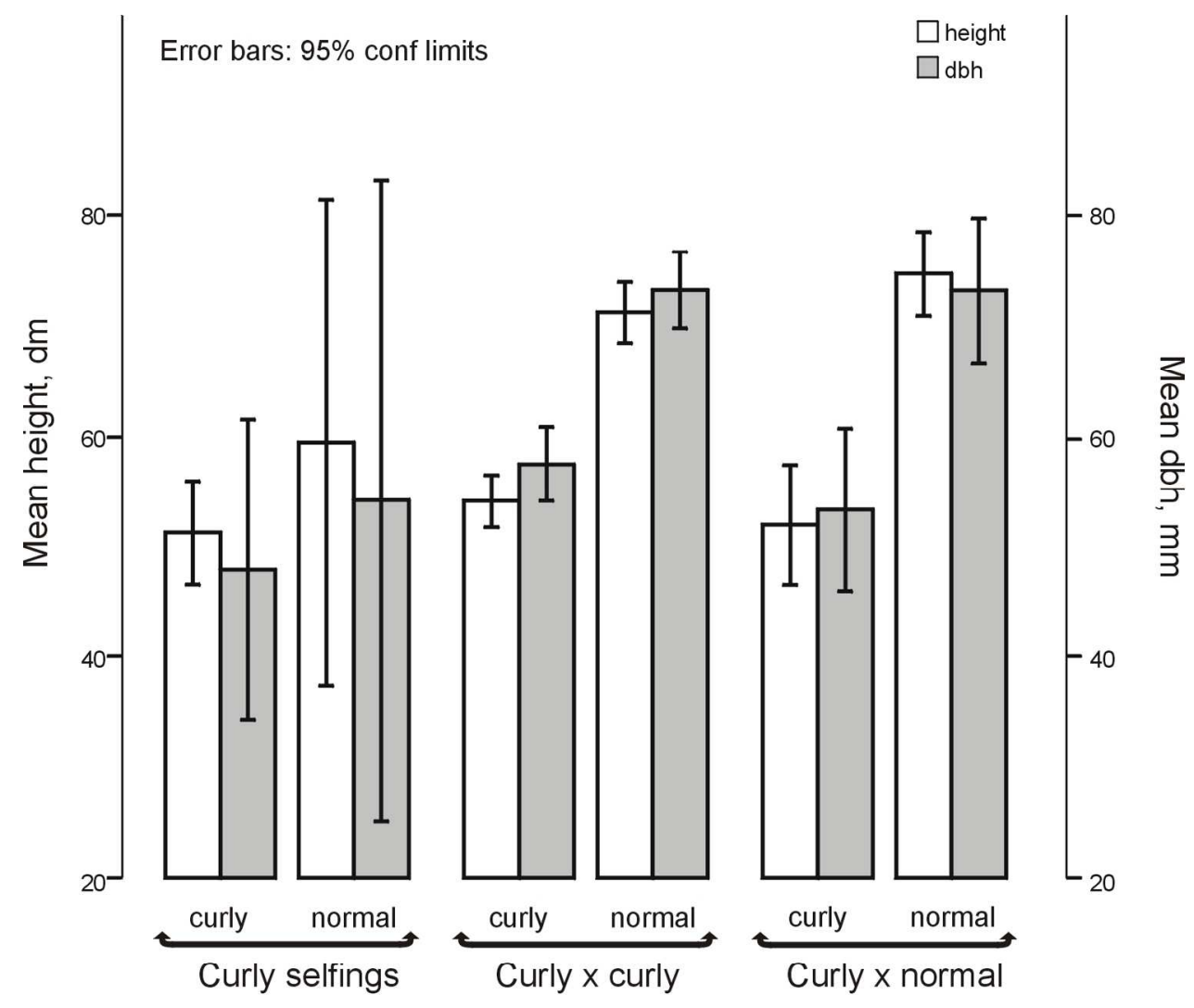

Figure 2. Mean height (white bars) and diameter (grey bars) of curly and normal, wild type individuals in the progenies of three crossing types.

$151 \times 133 \mathrm{~mm}(300 \times 300$ DPI $)$ 